\title{
The Issues and Challenges of Using Multimedia at a District Level, Specialized Girls' College in Bangladesh
}

\author{
Muhammad Hasan Sarowardy', Deb Proshad Halder ${ }^{2}$ \\ ${ }^{1}$ Jashore Government Girls' College, Jashore, Bangladesh \\ ${ }^{2}$ Department of English, Jashore Government Girls' College, Jashore, Bangladesh \\ Email: hasan13bcs@gmail.com, debproshadhalder@gmail.com
}

How to cite this paper: Sarowardy, M. H., \& Halder, D. P. (2019). The Issues and Challenges of Using Multimedia at a District Level, Specialized Girls' College in Bangladesh. Creative Education, 10, 1507-1524.

https://doi.org/10.4236/ce.2019.107110

Received: June 3, 2019

Accepted: July 13, 2019

Published: July 16, 2019

Copyright $\odot 2019$ by author(s) and Scientific Research Publishing Inc. This work is licensed under the Creative Commons Attribution International License (CC BY 4.0).

http://creativecommons.org/licenses/by/4.0/

\section{c) (7) Open Access}

\begin{abstract}
The use of multimedia in imparting education has inevitably been trendy owing to its multifold benefits which have been established and reinvestigated as inseparable teaching aid and tool in teaching-learning process. But This technological assisting component cannot be accorded in many of the institutions of Bangladesh due to several internal as well as external factors. This paper aims to highlight the emerging factors that beset in the institution of Bangladesh. This institutional study on the issues and challenges of using of multimedia in a district (urban area) level girls' college projects a thorough realization of the difficulties what this types of attributive colleges face in Bangladesh. The resource constraint, the lack of motivation of the teachers, the lack of expert human resource, the insufficient digital tools and lack of multimedia-enabled class environment are found to be barriers and some guiding directives are also imposed in this paper that emerges through the interviews of the teachers and the Vice principal. Thus, the paper, in a miniature effort, tries to lay out the challenges the college of Bangladesh faces and highlight some remedial ways to cope up the challenges.
\end{abstract}

\section{Keywords}

Multimedia, Challenges, Demotivation, Training, Pedagogy, Bangladesh

\section{Introduction}

The use of multimedia has claimed or has been claiming for a significant period of time as an integral part in the process of imparting as well as perceiving lessons in classroom. The new teaching method labors to make the lesson visualize by the students avoiding image construction in brains while receiving pictorial 
description in a text through listening and producing. A learner can visualize which enables a lesson more intelligible and durable as Penuel et al. (2000) contend that multimedia enabled teaching provides much scope to the learners to "organize, synthesize and develop" an eye-catching experience of visible contents that they perceived audibly (p. 34).

The title evidently specifies the study area as: 1) a girls' college, 2) the term "specialized" signifies as a government institution operated with government funding institution and 3) an institute in urban area in Bangladesh which imply that: 1) almost all the girls may have sorts of orientation with digital medium of learning due to its attribution as urban basis girls' college where the students are technologically advanced before reaching to adulthood as a study finds 140 million out of 160 million people in Bangladesh uses cell phone while 80 million have access to internet (Correspondent, 2017). This technological orientation has transformed the idea of conventional learning that a teacher cannot ignore as the learners represent a community which, in no way, a facilitator can overlook (Bransford et al., 2000), and 2) Education Policy-2010 and ICT Policy-2015 of the government of the People's Republic of Bangladesh aims at forming "young populace to resourceful ones" by introducing "multimedia classrooms" (Khanam et al, 2013) that validates to the fact that the government aids, in the best possible way, to facilitate with "equipment funding, professional development opportunities" (Penuel et al., 2000: p.36) and to keep up training to the teachers for continuous improvement for utilizing technological skills in classroom.

This paper identifies some issues and challenges of utilizing the thought of new multimedia assisted class presentation. It involves complex procedures to offer digital content presentation that demands the capability of an instructor for technology skills and content making knowledge. Along with this criteria, a teacher must catch the audience attention which enables that a teacher must show his pedagogical knowledge that he must ensure through the presentation.

An institute for education faces challenges on three folds: 1) learners or students, 2) instructors or teachers and lastly 3 ) the resources. This paper identifies through analyzing the findings that this institution requires resources to enable multimedia environment. But the greatest possibility of challenges is identified as the teachers. Penuel et al. (2000) admits that the prime obstacle to implementing a successful and learner effective multimedia class is the teachers. They face insufficiency of time to make a presentation, lack confidence to use it in class, gain little technical support to operate it and lack access to enough computers and other interfaces (p. 35). All these pose challenges in implementing multimedia class presentation as the institution owns some tools that a teacher can use at limited extent due to resource constraint.

The lack of habituation, demotivation and expert manpower are identified as some burning issues that impede a teacher to adopt modern viable orientation of teaching method, when resource constraint is not the sole impediment. 


\section{Literature Review}

The specific teaching strategy and learning tools determine the success of a class. Sun Protection Outreach Paper (n.d.) designates that concrete experience is more enduring and long lasting than only abstract lecturing of the issues (p. 7). This thought raises the possibility of disseminating information by the use of visual medium as human brain preserves visual information in long term memory and it bears tremendous capacity in containing the informations (p. 8). This ideation fosters the viability of integrating technological teaching orientation with the lecture methods in the case of conducting classes.

Escoe (2009) contends that technology contributes to the allowing of integration of various teaching strategies, i.e. "active learning", "cooperative learning", "writing-across-the-curriculum techniques" into a "seamless whole" (p. 275). Again the author is also suspicion on the fact whether visual orientation of teaching helps every student equally as a learner may have inclination more to be a visual learner whereas there is someone who is more prone to be an auditory learner (p. 226). Thus, the author tries to projects the idea which reveals that success of medium of imparting instruction largely depends on the way a learner receives the instruction more.

The recent brain research and neuroscience provides information that suffices the stant of visual learning though Escoe (2009) states a sort of doubt. The recent brain research emphasizes:

The human body is structured such that we take in more information visually than through all other senses (Wolfe, 2001). Visual displays help to foster attention, learning, and retention. The collective findings from learning and brain research support the benefits of graphics. Teachers who use graphics in their teaching and have students employ graphics (e.g., Overheads, PowerPoint presentations, demonstrations, drawings, concept maps, graphic organizers) capitalize on visual information processing and are apt to improve learning (Schunk, 2012: p. 67).

Thus, the definiteness of using multimedia for teaching instructions in order to have positive impact from the part of learners is affirmed and the reviews excerpted above provide strong evidence to dissuade the doubt of Escoe regarding the embrace of multimedia class operation to dig out more outcomes those were supposed to be rated lower in the lecture methods.

Class size is investigated to have marked an explicit impact on learning that a teacher needs to emphasize and an education investigator cannot overlook during examining whether a theory is applicable to the whole context. Addonizio \& Phelps (2000) contends that the fall of class size increases the rate of achievement of the students (p. 147). This is a perception, a small class size; a good rate of student achievement, refers to the Maimonides' rule, the biblical decision governing class size, which seeks enrolment of a teacher if the number of students in a class exceeds from forty to forty-one (Angrist \& Lavy, 1999). Mia (2001) contends that the Education policy of Bangladesh, the policy adopted by Ministry of Education, highlights this perception as mandatory to materialize through 
practical practice and so the Ministry designates that a teacher needs to be allocated as the excess of student enrolment to sixty-one from sixty (Asadulla, 2019: p. 7).

Asadulla (2019) expresses a sort of disbelief on the prior affirmation documented in the literature as Asadulla (2019) tends to state on logical grounds that class size and student achievement influences mostly on the elementary level students and small class size creates opportunity for a teacher to play active role all the time which may hamper student's wishful participation in class activities. Large class size creates scope for shared learning environment (p. $3-4)$. The class size is large in developing countries and it is not found that large class size hampers reaching significant level of achievement of the students in the specified levels (secondary and higher secondary levels) (p. 22). This findings by Asadulla extends and validates the possibility of a teacher's mediatory role and a student's textual learning that states a student's more scope to explore the texts or the presented context vividly that could have been overlooked due to large class size as only lecturing in a large class cannot ensure the attention from every student due to time constraint although the participation of every student in a class lecture necessitates the satisfactory achievement. Here, the use of multimedia in classroom (a large classroom in the developing country like Bangladesh) becomes validated as multimedia introduces a teacher as facilitator and raises the possibility of reaching to every student participating in the class and helps to distribute information properly as multimedia cannot be intervened in the midst of lectures by students' untoward activities (Xu, 2017: p. 193). This literature review is a justification, in the case of colleges with large class size, of using multimedia in class in order to make every student laden with knowledge.

Again, the institutional patronization to ensure multimedia based class from the part of the teachers does not mean to have solved the problems of traditional methods of teaching (lecture method, for instances). More issues are linked and many obstacles are to be faced to make multimedia class affective and effective. Multimedia class is researched to have made lessons easy to present, eased workloads of the teachers. But, Xu (2017) addressed to the thought emphatically that: 1) every lecture cannot be transformed to digitized form, 2) a teacher cannot add emotion and fodder for thought, emotive shifting of the learners, during multimedia presentation, 3) cartoon insert, animation add, graphics design in PowerPoint slides require advanced level of skills on computer that teachers often lack and 4) the multimedia presentation collapses due to electricity outage, software misbehavior etc. (p. 190) which externally hampers the class. These are not insignificant to address and the issues emerge, in most of the part, as challenges to tackle. An instructor is responsible enough to let the students utilize the utility service provided through the multimedia. This responsibility of a teacher creates challenges of using, successfully handling, multimedia in class as it is "inevitably advanced in teaching methods and poor in teaching effect" (Xu, 2017: p. 190). That's why; the guiding principle of Xu (2017) is to incorporate 
multimedia-enabled teaching method with lecture methods in order to retain the emotive values of pertaining class lectures. This thought addresses the challenge of the teachers how they can incorporate pedagogical knowledge with technological skills to add emotive values to the presentation.

Again, the usability of multimedia in classroom to disseminate information quickly and accurately has immediately been established and lots of literature defends in favor of the viability of these methods. But, the application and implementation of this method in classroom necessitate lots of things to integrate that may pose a barrier to establish multimedia classroom. Eskicioglu \& Kopec (2003) acknowledges that a multimedia-enabled (presentation of class lectures, texts, information with the help of multimedia) classroom environment congregates some tools; for instances, 'networked computers, storage devices, printers, scanners, LCD projectors, electronic whiteboards, digital camera and camcorders (p. 6). It is thus estimable how various external factors influence on establishing a multimedia classroom environment.

As per the context of the topic dealing with a few variables: using of multimedia, a college in a district level, issues and challenges etc. raise the issues of some other contextual matters, those must be considered if the question of materialization of multimedia-enabled class is resolved, like teacher's quality, class size, classroom environment. The literature review on the issue of implementing multimedia class favors this new methodological orientation indisputably where no one can express doubt of its positive effect on the students. But it has some visible challenges to combat for; it requires operational expertise on the part of the teachers and institutional efficiency to accord all the necessary tools for each class. These are the issues and challenges that a district level college in Bangladesh faces. Here lies the importance of justifying the credibility of the new method and the way of adoption of digital-enabled class practice in the context of Bangladesh.

Multimedia teaching has some limitations as it cannot be replaced by human beings. In their research, Zhang and Zhang (2013) studied the drawbacks and error of multimedia technology. They found that sometimes multimedia distract the attention of the students if the transmission is not done in a proper way. They opined that the management of multimedia must be developed. Again, they opined that the extent and assortment of digital contents and toolkits should be supervised and evaluated to ensure multimedia aided class. Their observation revealed that multimedia technology cannot work like human beings who can provide analysis to the students. They concluded, "Multimedia courseware cannot replace the knowledge inference and problem analysis by the blackboard; it cannot replace the two-way feedback mechanism on the information between the teachers and students." Moreover, Patel (2013) studied on the essence of multimedia technology on communication skill and found a lot to spend that time. Again, for the preparation of digital contents, both hardware and software technology knowledge is needed and many teachers lack this knowledge. Furthermore, it is not only the teachers who need technological 
knowledge; Torres opined that the students also need technological knowledge. Again he commented that the audiovisual aids that are incorporated in the multimedia should be evaluated appropriately.

Gao (2011) studies the problem of multimedia originate not from the tools; rather, the fully dependence on technology is a sign of lack of expertise on classroom management of them that may harm the natural environment of a class which may increase the probability of learning motivation among the students. Again, Deutscher (2009) found out the challenges of using multimedia especially within a science curriculum. The first problem of using multimedia technology as pointed by Deutscher is the technical problem. Sometimes it so happens that multimedia starts to malfunction because of technical problems. In such case, teachers become frustrated. Again, he found that most of the educational institutions do not have enough computers to provide for all the students. And, sometimes the teachers, as pointed by Deutscher, lose their motivation to use multimedia in the class. Moreover, Deutscher commented that most of the teachers are not updated to multimedia technology. They continue with the old learning materials which they prepared a long time ago. So Deutscher commented that variation in learning and teaching is lost. Moreover, $\mathrm{Hu} \& \mathrm{Xu}$ (2012) in their study found out why multimedia is not so successful even though it emerges as an advantage for instructors. However, in his work, he also pointed out the challenges of using multimedia. He found that teachers enriched with multimedia technology are rare. Authority has to pay a lot for their teachers so that they can develop their quality. Another challenge he pointed is the infrastructure related to the establishment of multimedia classroom. Importantly $\mathrm{Pa}$ tel observed, "While if totally dependent on, multimedia devices during teaching, the teachers may be turned into slaves to the multimedia and cannot play the leading role in teaching". He furthermore observed that sometimes teachers use multimedia so much that their role becomes very insignificant- they only play the multimedia. Again, he found that because of using multimedia students sometimes lack their speaking skill as they only listen to or watch the multimedia application. Torres (2017) also worked on the advantages and challenges of using multimedia in the classroom. He found that a lot of time is required to make the multimedia learning materials and the teachers are not eager which has may raise the probability of inattentiveness from the learners. They said that the teachers who use multimedia in the class ignore traditional teaching method altogether. Actually, according to the findings of these authors, traditional teaching method should be used with multimedia because using only multimedia does not help students' thinking power and creativity. The second drawback they found is that the multimedia content teachers use is not appropriate and high. Sometimes, teachers use very colorful images, videos etc. This hampers the concentration of the students. Thirdly they said that in many cases only the method has been change from traditional to modern but the main concept has remained the same. According to them, "teachers simply use multimedia to replace traditional chalk and blackboard. Their teaching more is 
still a simple injection." Multimedia-enabled learning through the presentation of digital contents by the instructors has to be implemented in education for the greater benefit of the students. However, Bandung, Gani, Tanuwidjaja, \& Sembiring (2015) found that there are some challenges in the way of spreading multimedia initiated learning. They found, "the challenges include electrical resources, networking, application software systems, human resources, hardware system, and risk management." Actually, creating the multimedia environment is the first challenge to spread multimedia learning.

That is to say, a multimedia-enabled class is priority in the process of imparting learning to the vested quarters. But the challenges remain and the degree and mode of challenges require equalized treatment.

\section{Methodology}

This paper intends to observe and critically analyze the perception and attitude of the teachers including the vice principal, one of the administrative personnel of the college, towards the use of multimedia in the classrooms and its intrinsic and extrinsic effect on the achievements of the students. Qualitative method approach suits for the purpose of exploratory study of the issues and challenges of using multimedia in a specified area, a college of district oriented. Because, it describes "a situation, phenomenon, problem or event" on nominal scale (Bernard, 1994: p. 2). Again, the few questions set in the questionnaire templates both for the teacher (questions No. 5, 6 and 7) and the vice principal (question No. 1) require predestined answers like "yes, no, satisfied, dissatisfied, etc.". These data will help to quantify how many teachers feel satisfied or unsatisfied with the total arrangements of multimedia in that college. This numerical judgement will help the college authority to focus on the matter of disturbance on the issue of multimedia classroom environment. This approach assonates the quantitative method of identifying the problems faced by how many of the respondents.

Thus, the paper incorporates mixed methods for the purpose to identify the number of the respondents aggrieved as well as to realize conception on the point of utility services in the college. This triangulation of qualitative and quantitative methods has deliberately made to enhance accuracy and meaningfulness of the conclusions and to have thorough state of situations (Teddlie \& Tashakkori, 2009: p. 7).

\subsection{Selection of the Study Area}

The researchers have chosen a Government Girls' College, which has been attributed as a specialized college due to the enormity of government subsidy in the case of establishing multimedia based classes, which resides in the hub of an urban area. The selection of this attributive institution as the study area is justified when the "gross enrollment of girls" in the secondary and higher secondary levels, "dramatic participation of girls in educational institutions" (Blunch \& Das, 
2015: p. 186) have been the center of focus among many of the researchers to measure: 1) what sort of provisions the girls' institutions provide, 2) what are the policies from the part of the government adopted in this institutions that attract female to enroll in these institutions and 3) how teachers are equipped in these institutions to retain the positive shift regarding girls' participation in schools and colleges. Blunch \& Das (2015) has also referred that the availability of communication technology has expedited mobility of the female and the easy access to technological devices has made this social transition (p. 188). World Bank (2008) has projected that no socio-religious barriers can hamper participation of female from institutional inclusion when the institution can implement "appropriate condition". This research paper aims to investigate whether the focused institution can materialize it. If the time and cost are justified for convenience, this institution is affordably reachable as this is the service area of the researchers and the investigation is conducted within the convening time. The urban level girls' college is a representative stratum in the scale of government provision, girls' enrollment rate and digital lab facilities. Thus the researchers have logical grounds to investigate the issues of using multimedia in this type of institutions and if there prevail any challenge to create appropriate conditions for girls aiming to get more probable and convincing ideas of imparting digital inclusive class room environment.

\subsection{Selection of Respondents}

The research question ascertains "the use of multimedia" in the pivotal position. And the users of multimedia in a class are the teachers, instructors and the target group of this research may be specified to the teachers who actively play the roles of utility service providers in a classroom. Twelve teachers have been purposively chosen as populations including Vice Principal, eight heads of the various departments and three general teachers who conduct ICT (Information and Communication Technology) classes. Vice Principal decides on administrative decision along with the Principal that means the Vice Principal has administrative influence on ensuring multimedia classroom environment, the heads of the department play managerial roles to inspire their colleagues or subordinate to inculcate the aptitude to present classes with multimedia. Thus, they have strategically been chosen to get the best outcomes regarding the answers for the research questions. The three more respondents are general teachers who have been assigned taking ICT classes and they have direct interaction with multimedia advised learning (Table 1 ).

\subsection{The Research Instruments}

Research instruments represent the tools which help the collection of data. This research paper initiates "Focus group interview" for the purpose of data collection. The two types of interview questionnaires have been appended at the last part of the paper that assisted as the tools of research. The questionnaires are 
Table 1. Respondents' categories and sample size.

\begin{tabular}{cccc}
\hline Sl No & Category of Sample & Sample Size & Selection Technique \\
\hline 1 & Vice Principal & 1 & Purposive Sampling \\
2 & Heads of Departments & 8 & Purposive Sampling \\
3 & ICT Teachers & 3 & Purposive Sampling \\
4 & Number of total respondents & 12 & - \\
\hline
\end{tabular}

loosely structured due to the nature of the research. These questions like to investigate the perceptions of the respondents on the use of multimedia and the challenges they face to fully establish this method as regular classroom practice. So, few questions on quantitative nature and rest of them on qualitative nature have been designed thus gives the shape of semi-structured questionnaires.

\subsection{Data Collection Procedures}

Questionnaire Survey method has been used for this study to collect the primary data. The necessary data of this study are collected through a close-ended and open-ended questionnaire (one is prepared for the vice principal and the other is prepared for the rest respondent teachers). This procedure is believed to have provided credible information as the researchers got enough time to build rapport with the respondents and the respondents were provided with the copies of questionnaires to provide feedback within a week as data collection procedures wanted to reach close to reliability and no manipulative responses. Researchers provided the questionnaire in unstructured and also structured formats to offer the scope of free thinking by the respondents to curtail the biasness of the researchers during picking up information that ensures nonprobability of fabricating the data (Schinke \& Gilchrist, 1993: p. 83). This research tends to identify whether this type of government subsidized institutions face the challenges of resource constraints, whether the respondents are positive to use multimedia in classroom, whether they feel demotivation to embrace this new shifting of lecture delivery. The interview of the respondents following the designed semi-structured questionnaire helped, in large scale, ensure feedback from $100 \%$ of the respondents.

Research papers of various researchers retrieved from internet have been used as secondary sources for review to collect data by the researchers of this paper which helped identify the challenges of materializing full-fledged multimedia-enabled classroom and initiate a comparative study of the challenges what this directed institution faces. The explorative and analytical procedures of secondary data are also followed to measure the extent and prominence of challenges this institution faces.

\subsection{Techniques of Data Analysis}

The procedure for the collection of data implies, largely, the technique of data 
analysis. The respondents or the targeted group are provided with semi-structured questionnaire including open-ended questions and structured multiple choice questions. Thus, the questionnaire serves the purpose of identifying the frequency of choices from the respondents as well as the attitudinal expressions emerged through open-ended question interviews. This paper chose the process of content analysis to describe the issues and challenges of using multimedia in classroom experienced by the respondents.

\section{Findings}

This part of the paper intends to present information through amalgamated data retrieved from the interview documents. The interview question template for the teachers comprise of ten more questions where stimuli no. 4, 8, 9 and 10 resembles structured type questions, though it lacks proper quality of structured questions, with option of "yes" - "no" answer providing a scope in this question to comment on the choice of the respondents. The other stimuli ripple simplistic opinion sharing open-ended responses (Table 2).

Again, the second questionnaire, which is appended at the end matter of the paper, designed for the Vice Principal has emphasized on enquiry and reflective basis which paves the way to describe, comment and observe the situation from the part of the respondent, here the Vice Principal by design. The overview of the contents documented as responses in the above table significantly expose several major findings which is needed to be discussed for the analysis later.

Table 2. Response rates of the respondents.

\begin{tabular}{|c|c|c|c|c|c|c|c|}
\hline Prompts & $\begin{array}{l}\text { Very Satisfied } \\
\text { Numericl rate }\end{array}$ & $\begin{array}{c}\text { Yes } \\
\text { Numericl rate }\end{array}$ & $\begin{array}{c}\text { Satisfied } \\
\text { Numeric/ rate }\end{array}$ & $\begin{array}{c}\text { No } \\
\text { Numericl rate }\end{array}$ & $\begin{array}{l}\text { Dissatisfied } \\
\text { Numericl rate }\end{array}$ & $\begin{array}{c}\text { Other } \\
\text { Numeric/ rate }\end{array}$ & $\begin{array}{l}\text { Very Dissatisfied } \\
\text { Numericl rate }\end{array}$ \\
\hline $\begin{array}{l}\text { Satisfaction on } \\
\text { using multimedia }\end{array}$ & - & - & $3 / 27.27$ & - & - & - & $8 / 72.73$ \\
\hline $\begin{array}{l}\text { The satisfaction of } \\
\text { students on teaching }\end{array}$ & - & $10 / 90.91$ & - & - & - & $1 / 9.09$ & - \\
\hline $\begin{array}{l}\text { Interest to } \\
\text { multimedia use }\end{array}$ & - & $11 / 100$ & - & - & - & - & - \\
\hline $\begin{array}{l}\text { Disinterest to } \\
\text { multimedia use }\end{array}$ & - & $8 / 72.73$ & - & $3 / 27.27$ & - & - & - \\
\hline $\begin{array}{l}\text { Large class to } \\
\text { require multimedia }\end{array}$ & - & $11 / 100$ & - & - & - & - & - \\
\hline $\begin{array}{l}\text { In house } \\
\text { Training }\end{array}$ & - & - & - & $11 / 100$ & - & - & - \\
\hline $\begin{array}{l}\text { The standard } \\
\text { of education }\end{array}$ & - & $7 / 58.33$ & - & $4 / 33.33$ & - & $1 / 8.33$ & - \\
\hline $\begin{array}{l}\text { Relationship between } \\
\text { results and digital class }\end{array}$ & - & $10 / 83.33$ & - & $1 / 8.33$ & - & $1 / 8.33$ & - \\
\hline
\end{tabular}




\subsection{The Findings on Satisfaction}

Two of the quarries (underlying in the question no. 1 and 9) on the teachers were related to the satisfaction of the teachers through the assortment of multimedia environment to conduct the classes and that of the learners at the class by the teachers. The eight teachers opined that they noted dissatisfaction with the arrangement for implementing multimedia class though the remaining three respondents remarked satisfied, which is rated $72.73 \%$ of dissatisfaction of total respondents.

Regarding to the response of the question no. nine "if the students like their presentation the methods they apply, all the participants except one respondent responded positively on the ground that the students took them positively in the class and are satisfied at what and how they presented". One of the respondents commented differently that he/she is satisfied with the sort of arrangements that the institution has made for the utilization in class. But the respondent could not provide direct answer to the matter of whether the learners are satisfied with the class and the tools the institution provides as these questions will claim more time to answer definitely. Time is a barrier as per the respondent's comment and so the participant could not answer whether the students are satisfied with the new modes of teaching provided by the institution.

The prompt five asks for opinion on the usability of multimedia in large class, which is a typical scenario of the institution attributed and specified in the "selection of study area part". All the respondents agree on the fact that digital presentation helps the teachers to control the large size class easily as they responded "yes" to the query.

\subsection{The Dimension of Interest to Use Multimedia}

The opening question tended to investigate the cause of interest to use multimedia by the teachers in a class and the question stated if the teacher felt interested in using multimedia. The eleven respondents agreed on their interest to use multimedia in class on these grounds that 1) it ensures standard education, 2) it raises the possibility of technology orientation in the students () time can properly be managed through multimedia class.

\subsection{The Perspective of Avoidance or Embrace to Multimedia}

Next, the respondents are asked as per the direction of the question no. three on why they avoid the use of digital content presentation in lieu of traditional textbook based direction in the classes by the teachers or tend to show fondness to do it, eight participants responded that they did not think of avoiding it and three respondents blamed on the insufficient digital amenities and poor infrastructure of the institution. It postulates that $72.73 \%$ teachers in this institution appraise integrating multimedia for class presentation whereas the other $27.27 \%$ teachers blame to the poor utility services and insufficient multimedia tools 
which result in their negligence to conduct multimedia-enabled class.

\subsection{A linkage to Multimedia and Satisfactory Results}

A stunning observation from the respondents as per the responses of prompts five and six has showed a strong linkage between the gradual increase of good results of the students and the establishment of multimedia class, though an alternative observation from a respondents prevail. Ten (that represents $83.33 \%$ of the respondents) respondents opined that: 1) the rate of good results is increasing, 2) the students are becoming more interactive and attentive, 3) the students are enjoying the class because of the blessing of multimedia class.

The other interview report refuses to claim the influence of multimedia in increasing good results of the students. The respondents admitted that the students were showing gradual shift to better results. But, the teacher opined that there was no investigation, that multimedia plays positive role, in the college to agree on the impact of multimedia for such kind of paradigm shift.

Again, the findings from the Vice Principal regarding the improvement of assessment of the students are noticed to have prioritized on several matters where he never addressed the necessity of using multimedia in the classes (the third question interrogates' whether he thinks use of multimedia raises the performance of the learners he avoids this question from responding) as he discerns: 1) the regular attendance of the learners, 2) attentiveness and the following of instructions given by the instructors, 3) emphasis on group work and assessment system after lesson are criteria for achieving the satisfactory level of pass that implies cent percent of pass of the learners.

\subsection{Non Participation at In-House Training}

The noticeable findings needs to be addressed here that no respondents attended in-housetraining (the in-house training contains the idea of participating in training sessions arranged by the institution administration in the institution conducted by a teacher who has presently taken part in training out of the institution).

However, the findings from the interview of Vice Principal designate a few causes behind the reluctance of in-house training by the teachers as: 1) the institution has not yet enabled to ensure "one man, one laptop" facility in the training lab and 2) the training cannot focus on continuous development of the teachers in the case of Incorporating multimedia with previously applied methods.

\subsection{Budget and Manpower}

The issue of budget and man power has strongly been addressed by the Vice Principal. The interview report informs that the idea of multimedia classroom depends largely on budgetary allocation and the skilled man power according to Him. He finds the institution faces challenges for these two reasons to apply 
multimedia approach. The Vice Principal, being one of the administrative personnel, reports some means and ways to materialize multimedia inclusive class system as he opines 1) allocation of government and internal funds more in this sector and 2) grants from external sources are to be prioritized.

\section{Analysis}

The findings have been duly stated and this portion tends to critically analyze and evaluate the attitudinal shift of the respondents. This is totally content based analysis and the attitude, the biasness; the activities initiated have been measured which helps to designate the challenges of using multimedia in classroom faced and stated by the teachers (respondents).

\subsection{No Discordance on the Utility of Multimedia}

The findings prove the reluctance from the parts of the teachers to take part in digital content presentation training, to use multimedia during class etc.; but, all the respondents took for granted of the ideation that multimedia turns to be integral part of teaching-learning process. Their observation resonates the decision of the Sun Protection Outreach Paper (n.d.) which directs to the belief on the more durability of multimedia presentation-enabled teaching more than abstract lecturing. So, it a positive sign that the teachers of this institution have, in any way, been baptized with the idea of effectiveness of using multimedia in teaching-learning process.

\subsection{The Problem Prevails}

A data on the rate of favor (72.73\%) of multimedia class expresses positive attitude to this new trend of teaching method. But it does not mean that $72.73 \%$ teachers of this institution apply new technique for disseminating new system. Because, the teachers face insufficiency of teaching aids and shortage of expert person to maintain this total digital system. The findings of Patel (2013) seem befitting here as the researcher (Patel) comments "teachers rich with technology expertise are rare". This is one of the greatest challenges this institution faces as per the observation of the findings. If the institution lacks technology expert teachers, it is imperative the institution arranges training for the teachers. And the findings show the institution arranges in-house training for the teachers. Then, the root of the problem is otherwise. The teachers have inferentially referred that this institution lacks sufficiency of teaching aids that implies poor environment that provides little privilege for the teachers to practice through operating the tools which Deutscher (2009) has opined in his paper.

\subsection{The Impact of Multimedia on Results}

The "impact" test of multimedia on the results of an institution requires lots of structured process to follow. It implies: 1) analyzing the result records of the students, 2) recording/taking notes of the yearly shift of results, 3) comparative 
discussion of the results between the years before the introducing of multimedia and those of the years after that of multimedia. For the sake of this paper (owing to the nature of the research), this paper relies on the comments from the teachers as well as the Vice Principal. All the respondents including the Vice Principal expressed the same consent regarding the improvement of results noticed over the few years along with the arrangement of projector based class, computer aided teaching, several in house and out of institution training. Though the Vice Principal and one of the respondents escape the question of direct link between progressing results and multimedia introducing, there prevail lots of reasons to defend the thought. Because, the teachers remain same, the institution has not adopted any other significant methods to utilize on the students, the students hail from same characteristic environmental/socio-economic factors as it became previous years. But one factor experienced change: the teachers are being introduced with the digital method of teaching and the teachers have received several out of institutional training arranged and funded by the government and they are oriented with the thought how to develop digital content, the institution are gradually being decorated with the amenities of multimedia tools. Thus, this two dimensional correlational link: 1) the teachers and 2) institution) on the basis of adopting multimedia operational ideology may influence the students and this influence shows its revelation through the positive outcome of the results of the students. But it is again acknowledged this is an analysis of the findings provided by the teachers who are stratified on the basis of several criteria to serve the purpose of the research. This analysis aims to discern whether the teachers are being oriented with new methods, whether they nourish a positive outlook regarding this new trend in teaching practice.

\subsection{The Questionable Capacity Building}

The implementation of multimedia-enabled classroom requires lots of things to consider. The literature reviewed explained how this method incorporates lots of considerable issues. Xu (2017) mentions that a multimedia based teaching cannot help implying: 1) correctly understandability and reasonably treatment of multimedia teaching, 2) avoidance of the blindness of multimedia construction and use, 3) increasing the quality of courseware, 4) promoting teacher's professional level and classroom dynamics and 5) organically combination of traditional and multimedia teaching. The data findings project the opposite picture of capacity that the institution provides. The respondents admitted the resource constraints in this institution. One thing should be noted that the issue of pedagogical knowledge of the teachers along with technological expertise. The teachers have to manage large class that imply they should properly create inclusiveness, retain the attention of the learners and make the class interactive through synthesizing a multimedia and traditional method. The findings show the teachers have demotivation to take part in house training on multimedia operation and resource scarcity which is one of the greatest challenges the institution faces. 
The institution and the instructors possess positive outlook for multimedia class. But the challenges remain: resource insufficiency, lack of resourceful manpower is two of the challenges that the institution has to face and has already been facing.

\section{Conclusion and Recommendation}

The issues of using multimedia in an institute, specialized and characterized, in the context of Bangladesh are manifolds that the findings of the paper presents. The global education is rapidly embracing the new trends of teaching methods and this paper aims to judge the capacity of this type of institutions in Bangladesh whether they excel in capacity measures. Multimedia enabled tools are prior requirement that all admit without debate. But this paper finds other more issues except the availability of tools to address. the lack of expert human assistance to support the teachers with power point management (as it has been reviewed that a teacher cannot reach to that expertise of digital tools management in a class), the large class size of students, and more necessarily the ability of instructors to combine the traditional lecture method with the new multimedia class presentation approach.

\subsection{Recommendation}

This institution cannot proceed without addressing the challenges of implementing multimedia method class. The analysis of the findings demands some recommendations to implement this mode of teaching as:

1) The teachers must establish trust in this type of teaching method.

2) The college administration must focus on quantitative and qualitative research to determine the positive relationship between multimedia class lecture and the good results of the students to retain the trust of the teachers.

3) The teachers must be remunerated with incentives to create digital contents that will increase the capability of the teachers to make digital contents for class.

4) Training must ensure the combination of pedagogical and technological knowledge of the teacher to retain the interest of the students for the class.

5) This institution claims some expert people on technology who can assist any teacher providing with technical support to the teachers regarding multimedia operation.

The investigation agrees on the resource constraint that this institution faces. But the college administration is hopeful on the fact that they can claim more budgetary allocation from the government and they can proceed to more other options to accord finances as the dissemination of content information by the assistance of multimedia in classroom is now a reality.

\subsection{Concluding Remark}

The paper does not project only to the idea of the significance of multimedia enriched classroom, it enables to focus on the duties and responsibilities of the 
instructors. The prime beneficiaries are the students and it largely depends on the teachers. Multimedia is machine or tools and the teachers can add motion and emotion in these tools and they can make any type of method successful through raising attentiveness, increasing interaction and providing emotive aspect to a lesson. So to say, pedagogical knowledge and technological expertise needs to be incorporated in a teacher and for which training for the teachers is priority that will enable the instructors: 1) correctly understand the impact of multimedia, 2) reasonably treat multimedia teaching, 3) avoid the blindness of multimedia construction and use, 4) increase the quality of courseware 5) and finally promote teacher's professional level and classroom dynamics (Xu, 2017). Thus, tools are accorded in a time, but the teachers ensure the utility from these tools and they bride among methods and students and the research, and accordingly, the focus should be bestowed on the investigation of the challenges the teachers face and the probable guiding ways to tackle those challenges.

\section{Conflicts of Interest}

The authors declare no conflicts of interest regarding the publication of this paper.

\section{References}

Addonizio, M., \& Phelps, J. (2000). Class Size and Student Performance: A Framework for Policy Analysis. Journal of Education Finance, 26, 135-156. https://www.jstor.org/stable/40704119

Angrist, J., \& Lavy, V. (1999). Using Maimonides' Rule to Estimate the Effect of Class Size on Scholastic Achievement. Quarterly Journal of Economics, 114, 533-575. https://doi.org/10.1162/003355399556061

Asadullah, M. (2019). Class Size and Student Achievement in Developing Countries: Evidence from Bangladesh. https://www.researchgate.net/publication/228858655

Bandung, Y., Gani, A. M., Tanuwidjaja, H. C., \& Sembiring, J. (2015). The Challenges of Delivering Multimedia-Based Learning Services in Rural Areas. In 2015 International Conference on Information Technology Systems and Innovation (pp. 1-6). Piscataway, NJ: IEEE. https://doi.org/10.1109/ICITSI.2015.7437701

Bernard, H. R. (1994). Research Methods in Anthropology: Qualitative and Quantitative Approaches (2nd ed.). Thousand Oaks, CA: Sage.

Blunch, N. H., \& Das, M. B. (2015). Changing Norms about Gender Inequality in Education: Evidence from Bangladesh. Demographic Research, 32, 183-218.

http://www.demographic-research.org/Volumes/Vol32/6 https://doi.org/10.4054/DemRes.2015.32.6

Bransford, J. D., Brown, A. L., \& Cocking, L. R. (2000). How People Learn: Brain, Mind, Experience and School: Expanded Edition. Washington DC: The National Academies Press. https://doi.org/10.17226/9853

Correspondent, S. (2017). Mobile Phone Users in Bangladesh Top 140 Million. Bangladesh News 24 Hours Limited.

https://bdnews24.com/business/2017/11/14/mobile-phone-users-in-bangladesh-top-14 $\underline{0 \text {-million }}$ 
Deutscher, R. (2009). Challenges Using Multimedia Integrated within a Science Curriculum Using a Classroom-Centered Design Approach.

https://www.deltaeducation.com/resources/blog/sep-2009/challenges-using-multimedia

Escoe, G. M. (2009). Multimedia Instruction Methods: Comment. The Journal of Economic Education, 30, 275-276. https://www.jstor.org/stable/1183065 https://doi.org/10.2307/1183065

Eskicioglu, A. M., \& Kopec, D. (2003). The Ideal Multimedia-Enabled Classroom: Perspectives from Psychology, Education and Information Science.

Gao, Z. (2011). Problems and Solutions of Multimedia Aided College English Teaching. In Proceeding of the International Conference on e-Education, Entertainment and e-Management (pp. 141-143). Piscataway, NJ: IEEE.

Hu, M., \& Xu, S. (2012). Research of Multimedia Teaching on Principles of Management. IERI Procedia, 2, 666-670. https://doi.org/10.1016/j.ieri.2012.06.151

Khanam, R., Monem, M., Howlader, S. R., Ahmed, F., Ahsan, N., \& Abedin, A. M. J. (2013). "Assessment of Multimedia Classroom (MMC) and Teacher -Led Content Development”: Access to Information (A2I). https://a2i.gov.bd/wp-content/uploads/2017/10/6-Report-assessment-of-multimedia-cl assrooms-mmc-and-teacher-led-content-development.pdf

Mia, S. R. (2001). Non-Government School Establishment Guide. Dhaka: New Warsi Book Corporation.

Patel, C. (2013). Use of Multimedia Technology in Teaching and Learning Communication Skill: An Analysis. International Journal of Advancements in Research \& Technology, 2, 116-123.

Penuel, W. R., Means, B., \& Simkins, M. (2000). Teaching the Information Generation. Educational Leadership, 58, 34-38.

Schinke, S. P., \& Gilchrist, L. (1993). Ethics in Research. In R. M. Grinnell (Ed.), Social Work, Research and Evaluation (4th ed.). Itasca, IL: F.E. Peacock.

Schunk, D. H. (2012). Learning Theories: An Educational Perspective (6th ed.). Boston, MA: Pearson.

http://repository.umpwr.ac.id:8080/bitstream/handle/123456789/96/\%5BDale_H._Schu nk\%5D_Learning_Theories_An_Educational..pdf?sequence $=1$ \&isAllowed $=\mathrm{y}$

Sun Protection Outreach by Students (n.d.). The Adolescent Brain-Learning Strategies and Teaching Tips.

http://spots.wustl.edu/SPOTS\%20manual\%20Final/SPOTS\%20Manual\%204\%20Learni ng\%20Strategies.pdf

Teddlie, C. B., \& Tashakkori, A. (2009). Foundations of Mixed Methods Research: Integrating Quantitative and Qualitative Approaches to Social and Behavioural Sciences. Los Angeles, CA: Sage.

Torres, J. A. (2017). Advantages, Challenges Encountered and Attitude of Teachers in Utilizing Multimedia in the Classroom. Journal of Social Sciences, 6, 348-356. https://doi.org/10.25255/jss.2017.6.2.348.356

Wolfe, P. (2001). Brain Matter: Translating Research into Classroom Practice. Alexandria: Association for Supervision and Curriculum Development.

World Bank (2008). Whispers to Voices: Gender and Social Transformation in Bangladesh. Dhaka and Washington DC.

$\mathrm{Xu}, \mathrm{X}$. (2017). Study on Effective Using of Multimedia Teaching System and Enhancing Teaching Effect. International Journal of Emerging Technologies in Learning, 12, 187-195. https://doi.org/10.3991/ijet.v12i06.7093 
Zhang, J., \& Zhang, Z. (2013). The Limitations and Application Errors in Multimedia Teaching of College. In 2012 First National Conference for Engineering Sciences (pp. 6). Paris: Atlantis Press. https://doi.org/10.2991/icetms.2013.180

\section{Appendix}

\section{Questions for Interview (Teachers)}

1) What do you feel using multimedia in class?

(a) Very satisfied (b) Satisfied (c) Dissatisfied (d) very dissatisfied (e) other.

2) Why are you inspired to use multimedia in class? (If you use)

3) Why do you avoid multimedia presentation in class? (If you avoid)

4) Why do most of the teachers feel reluctant to use multimedia in class?

5) Does large class size necessitates multimedia? If "Yes", Why?

6) Which area does multimedia influence directly in student achievement test?

$7)$ Do exam results improve through using multimedia in class? If Yes, Why?

8) Have you participated in house training on the use of multimedia?

(a) Yes (b) No (c) Other

9) Do you think students are satisfied in your class?

(a) Yes (b) No (c) Other

10) Do you think this college provides standard education?

(a) Yes (b) No (c) Other

\section{Questions for interview (Vice Principal)}

1) Do you think this college provides standard education?

2) What are the causes behind praiseworthy rate of results of the students of your institution?

3) What do you think the ways to improve the results of examination?

4) What are the pictures of using multimedia in this college?

5) What are the issues and challenges to ensure multimedia based classroom in this college?

6) What are the impediments to ensure multimedia based classroom in your college?

7) How do we ensure multimedia classroom in this college? 